\title{
Supplemental Instruction and Academic Success and Retention in Science Courses at a Hispanic-serving Institution
}

\author{
Vanessa B. Meling ${ }^{1}$, Marie-Anne Mundy ${ }^{2}$, Lori Kupczynski ${ }^{2}{ }^{*}$ \& Mary E. Green ${ }^{2}$ \\ ${ }^{1}$ Department of Student Success, Our Lady of the Lake University, USA \\ ${ }^{2}$ Department of Educational Leadership and Counseling, Texas A\&M University-Kingsville, USA \\ *Corresponding author: Department of Educational Leadership and Counseling, Texas A\&M University-Kingsville, \\ Kingsville, TX, 78363, USA. Tel: 1-956-648-7617. E-mail: kulpk000@tamuk.edu
}

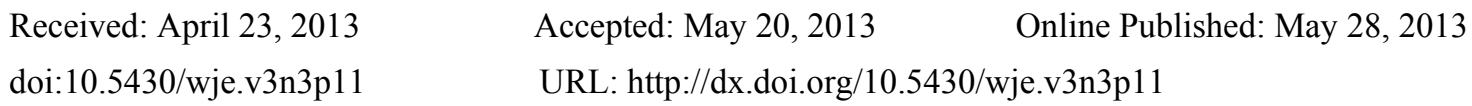

\begin{abstract}
This study provides insight into the effectiveness of Supplemental Instruction (SI) at a Hispanic-serving institution (HSI), particularly with Hispanic students. The United States Department of Education (2010) defines an HSI as having a $25 \%$ or greater full-time, Hispanic student enrollment and $50 \%$ or more of all students are eligible for need-based financial aid. It is essential for many Hispanic-serving institutions (HSIs) that have a high percentage of Hispanic populations to find ways where they will support and retain a growing number of minority degree-seeking students. One of the biggest challenges for HSIs is not only increasing retention, but additionally supporting the Science, Technology, Engineering, and Math (STEM) courses at these institutions. The study contributes to the existing research that shows that SI is an effective student success intervention in improving academic success and course retention among Hispanic students in STEM related courses. The results showed a significant difference in academic success and course completion among Hispanic students at an HSI with SI participation in Chemistry and Physics courses.
\end{abstract}

Keywords: supplemental instruction; SI; Hispanic-serving institution; STEM; Hispanic Students; academic success

\section{Introduction}

As the population of Hispanics grew dramatically in the United States from 35 million in 2000 to 46 million in 2008 (US Bureau of Census, 2010a) there has been a corresponding increase in Hispanic students attending college from 1.4 million to 2.1 million (US Bureau of Census, 2010b). Many students from this population are choosing to attend higher education institutions that fall into a small consortium of colleges and universities that are called Hispanic-serving institutions (HSIs) (Laden, 2004). The definition of Hispanic-serving institution varies among organizations. The Hispanic Association of Colleges and Universities (HACU) defines it as a college or university that has a total Hispanic enrollment of at least $25 \%$, consisting of full-time and part-time students at the undergraduate or graduate level or both, including professional schools (2010). The United States Department of Education (2010) defines an HSI as having a 25\% or greater full-time, Hispanic student enrollment and 50\% or more of all students are eligible for need-based financial aid. With Hispanic-serving institutions making up seven percent of colleges and universities in the United States and enrolling 54\% of Hispanic undergraduate students, they are faced with many challenges in educating one of the largest and fastest growing minority groups (Santiago, 2008a; Perrakis \& Hagedorn, 2010; Haegedorn, Chi, Cepeda, \& McLain, 2007).

According to the American College Testing (ACT) research report (2010), retention rates continue to decline at public four-year institutions with a current overall retention rate of $74 \%$. Retention among minority students, primarily Hispanic students, is a great concern due to its decreasing rates. According to the United States Department of Education National Center for Education Statistics (2011), approximately 51\% of Hispanic students cannot complete their bachelor's degree over a six year period. Although 38\% of all bachelor's degrees given to Hispanics in 2001 were awarded by HSIs (National Science Foundation, 2009), only 13\% were science, technology, engineering, and math (STEM) degrees (Anderson \& Kim, 2006). With national attention on retention and graduation rates and federal-state initiatives being placed on the STEM pipeline, there is a great need for academic 
support programs that are not only cost-effective but increase student success and retention in science at HSIs.

Historically, research has indicated that academic integration for minority students is important in order to see an increase in retention and eventually graduation (Tinto, 1986; Terenzini, 1994). Academic support programs are one way of integrating academics outside of the classroom for students at Hispanic-serving institutions as they not only increase student success and degree completion rates, but also give students a sense of belonging (Gastic \& Nieto, 2010; Maestas, Vaquera \& Zehr, 2007). Student success is possible when HSIs tailor to student needs and connect student support services with academic programs (Gastic \& Nieto, 2010; Benitez \& DeAro, 2004).

Kuh, Cruce, Shoup, Kinzie, and Gonyea (2008) suggested in their study on persistence and success of underrepresented students to use active and collaborative learning approaches in higher education campuses in order to foster student learning among underrepresented students. Collaborative learning, as peer learning, functions without a staff or teacher being present to control the learning; it is dependent upon peers teaching one another (Boud, Cohen, and Sampson, 1999). Collaborative learning can be used in various subjects and fields in higher education, more than ever in the sciences. According to Bell, Urhahne, Schanze, and Ploetzner (2010), collaborative inquiry learning involves nine processes that students in the sciences go through. These include: 1) orienting and asking questions, 2) hypothesis generation, 3) planning, 4) investigation, 5) analysis and interpretation, 6) model exploration and creation, 7) conclusion and evaluation activities, 8) communication, and 9) prediction.

In evaluating academic support programs, ACT (2010) gave a list of 94 programs, services, curricular offerings, and interventions that impact retention to 2,500 public, four-year institutions around the country and asked university leaders to rate the degree in which these practices impacted retention. The Supplemental Instruction (SI) program was consistently selected as one of the top three practices that have the greatest contribution to retention on college campuses (ACT, 2010).

Supplemental Instruction is a nationally recognized academic support program that assists in increasing student learning as student's master course content while developing study skills that are applied to that course and future courses (Blanc, Debuhr \& Martin, 1983). Created in 1973 by Deanna Martin at the University of Missouri-Kansas City (UMKC), it began with a simple phone call in response to attrition issues among minority students in the health science schools (Widmar, 1994). More than thirty years later, the Supplemental Instruction model continues to impact minority student success as it provides regularly scheduled, peer-facilitated, voluntary sessions for all students in difficult courses (Hurley, Jacobs, \& Gilbert, 2006).

McGee (2005) found in his study on the relationship of demographic variables with engagement in SI, that Hispanic students engage in SI at a higher level than White students. The study took place on a predominantly White student campus, where minority students could easily feel marginalized even within academic support programs. The results of the study pointed to SI's efficacy in engaging minority students, particularly with engaging Hispanic students. An earlier study examined a SI program at Cornell University where they offered the program to students who were members of ethnic groups or from disadvantaged backgrounds (Collins, 1982). The results showed that even when the SAT scores and high school rank were held constant in a multiple regression procedure, SI attendance made a significant difference in the academic achievement with the individual course (Biology, Chemistry, and Mathematics) and the student's overall cumulative grade point average. Minority students who attend SI regularly receive higher grades when compared with the non-SI participants. Despite these studies, there is minimal research on the impact SI has on retention or academic success at HSIs where there is more than a $25 \%$ Hispanic student population.

The Hispanic-serving institution in this study received a federal grant awarded to HSIs that proposed to address science, technology, engineering, and mathematics (STEM) education. The grant's intent of was to increase the number of Hispanic and low income students attaining degrees in STEM fields. Given that research has shown that Supplemental Instruction has been effective in increasing success in science (Parkinson, 2009; Rath et al., 2007; Kenney \& Kallison, 1994; Shaya, Petty, \& Petty, 1993), it was chosen as the academic support program to be implemented. This study's purpose was to determine if Supplemental Instruction affected final grades in science courses and course completion among Hispanic students at a public, four-year south Texas HSIs.

The following research questions guided the study:

1) Does the number of SI session levels have an effect on the final course grade in physics and chemistry for Hispanic students?

2) What are the main effects of supplemental instruction and gender on physics course completion and is there any interaction between instruction and gender? 
3) What are the main effects of supplemental instruction and gender on chemistry course completion and is there any interaction between instruction and gender?

\section{Literature Review}

\subsection{The Retention Framework}

Traditional retention theory has been discussed and implemented in many institutions of higher education, yet the gap between White college students and minority, low-income students remains wide (Oseguera, Locks, \& Vega, 2009). With the increase of minority and low income students on college campuses, it is imperative to bridge the gap between White students and minorities in order to meet future challenges our country faces both globally and economically (McGlynn, 2008, p 42). In comparison with other ethnic groups, Hispanic students are delaying their enrollment into college, thus delaying graduation (Cerna, Perez, \& Saenz, 2009).

While there has been much research done in the area of retention that has contributed to our understanding of student drop out behavior, there has been limited success with minority students due to attempts of fitting the White student experience into all other student experiences (Oseguera et al., 2009). One of the factors that make a difference in minority retention rates is the attention placed in knowing and understanding these students (McGlynn, 2008). In the past, researchers have held social context, ethnic identity, and gender as controlled variables when examining retention instead of focusing on these significant areas that influence educational outcomes (Oseguera et al, 2009).

\subsection{Retention and the Campus Climate}

Ethnic identity and culture have a strong influence on student persistence and when students encounter hostile environments that are culturally exclusive there is a major disconnect (Torres, 2006). There is a great responsibility for institutions to offer inclusive and encouraging campus climates for Hispanic students. Institutions of higher education must adopt a re-conceptualization of success when working with Hispanic students and increasing retention rates.

Latino students who have positive interactions with diverse peers during college and participation in academic support programs are found to have a stronger sense of belonging (Hurtado \& Ponjuan, 2005). Participating in academic support programs builds confidence allowing Latino students to practice developing analytical skills during their early years of college. Support structures through academic programs can benefit students by increasing skills and confidence, while decreasing the sense of marginalization many students experience as first year college students (Hurtado \& Ponjuan, 2005).

\subsection{Community and Hispanic Student Retention}

When studying the multicultural influence on group learning, Sweeney, Weaven, and Herington (2008) ultimately found in their study on international students perception of collaborative work that most respondents showed to have a positive perspective on their personal skill development and higher order learning from the group. Having structure and instruction in group dynamics and collaboration dissolved any preconceived notions students had on group work. Morgan (2004) proposed that group examinations and group grades among cooperative learning circles have a stronger, positive effect on Hispanic undergraduate students than non-Hispanic undergraduates. The study found the group examination and grading to build a supportive environment, increased trust and respect for peers, and a deeper understanding of content for Hispanic undergraduate students. Consequently, this environment also created a higher concern for responsibility with their team and a higher rate of stress with their own preparation level before an exam (Morgan, 2004).

\subsection{Academic Barriers}

Minority students commonly enter into college with lower achievement entrance examination scores (Green, 2006). Fischer (2007) suggested in her study on minority students and college transition, that in the academic realm, minority students (Blacks, Hispanics, and Asians) who had better preparation prior to college received better college grades. Moreover, being connected with faculty increased these students' grades. Seeking out academic enrichment programs had a positive impact on grade point averages, particularly for Hispanic students who were underprepared from high school (Fischer, 2007). Receiving study skills training while in college has been found to be helpful for Hispanic students (Longerbeam, Sedlacek, \& Alatorre, 2004; Fuertes \& Sedlacek, 1995).

\subsection{Economic Barriers}

Hispanic students are entering college with the lowest average socio-economic statuses among minorities; as a result, 
this affects their access to information, quality of education, and educational performance (O'Connor, 2009). Many Hispanic students are employed off-campus so that they are able to meet their living and educational expenses.

First-generation college students work more hours than their counterparts and are involved in less extracurricular activities with their peers. These activities could help engage students in the institution (Pascarella, Pierson, Wolniak, \& Terenzini, 2004). Pasceralla et al., (2004) found that although first generation students are less involved in extracurricular activities in college, their involvement in their own social groups does positively impact their own sense of control over their academic success.

\subsection{The STEM Education Pipeline at HSIs}

The United States must focus on the institutions that are recruiting and educating the fastest growing population in the US, Hispanic-serving institutions, in order to compete globally in the areas of Science, Technology, Engineering, and Math (STEM), its (Gates, 2010). Over the years the challenge for underrepresented students in STEM programs has been to engage in academic support programs that increase learning and achievement without stigmatizing students with remedial status as they enter into college for the first time (Seymour \& Hewitt, 1997; Seymour, 2002). A shift from traditional, lecture-based classes to a more collaborative, activity-based learning environment has emerged in STEM courses and the focus has evolved from teaching to learning (Seymour, 2002). Implementing innovative practices that increase student learning, academic success, retention, and degree attainment are critical for strengthening the STEM pipeline at HSIs.

Crisp, Nora, and Taggert (2009) discovered in their study that Hispanic students at HSIs have a high representation in STEM majors. Moreover, when compared to white students, Hispanic students' financial support, parental education, and math SAT scores do not make a difference when choosing a STEM major. Despite this study, the financial strain of college is a reality for many Hispanic students earning STEM degrees; HSIs have the opportunity to increase the knowledge of financial aid and decrease the dependence many students have on loans (Violino, 2011).

\subsection{Academic Support Programs at HSIs}

With President Obama's 2020 college graduation initiative, HSIs are in a critical position to promote post-secondary opportunity and create an economic recovery among Hispanic students. In their study, Gastic and Nieto (2010) maintain that successful HSIs incorporate student support services with academic programs in order to build effective support environments around their students. Academic enhancement programming increases student degree completion at HSIs and contributes to student success.

Tinto (1994) confirmed that concepts of academic and social integration play a critical role in creating a sense of belonging for students. Maestas et al. (2007) sought to discover factors that build a connection with students and found that students who were involved in academic support programs had an increased sense of belonging. Having a supportive academic network in diverse environments increases the students' connection with the university, which in turn, impacts their retention at the institution. Additionally, Maestas et al. (2007) found that faculty and student interactions build a greater sense of belonging.

\subsection{Supplemental Instruction: An Exemplary Academic Support Program}

The Supplemental Instruction (SI) program has been implemented and accepted at many institutions around the country. With the implementation of SI in over 800 colleges and universities in the US and around the world, there is evidence of the value and positive impact the program has had on students (Congos, 2002). Supplemental Instruction is one academic support program that requires the program supervisors to measure its impact and outcomes semester by semester. With this high expectation among SI programs, SI supervisors are equipped with researched assessments that can be manipulated to result in anecdotal information, descriptive statistics, and inferential statistics (Congos \& Schoeps, 1999)

SI programs identify high-risk courses that would benefit from having a structured study session offered to students. Courses that are identified as high-risk are courses that students label as "killer" courses and they have been identified as general education courses where there is a $30 \%$ or higher of $\mathrm{D}, \mathrm{F}$, and withdrawals from students in the course (Blanc, Debuhr \& Martin, 1983). The group study sessions are offered with an emphasis on course content, not because of the difficulty of the professor, but instead because of the difficulty of the subject matter. In the study sessions there is an effort to merge content with practice and to connect learning strategies to the course material (Blanc \& Martin, 1994).

One of the key qualities that Supplemental Instruction sessions offer to students is a place where students can come together to study and learn from each other. Students are placed in a more active role in processing information and 
they are given ownership over their own learning. Wilcox \& Koehler (1996) characterize the process as student engagement; while students engage one another with questions the process develops critical thinking skills instead of passive learning. Research shows students who attend Supplemental Instruction progress from only being passive listeners to being active processors of information and later develop into critical thinkers (Congos, 2002; Wolfe, 1987).

\subsection{Science Success}

Retaining and graduating minority students and females in the sciences is a feat that the U.S. government and higher education institutions have taken on for many years. The support of Supplemental Instruction through small group skill development has proven to make positive waves in learning scientific concepts and problem-solving among underrepresented students, which include women and minority students (Lundberg, 1995; Rath et al., 2007; Shaya, Petty, \& Petty, 1993). Supplemental Instruction can be applied to a diverse scale of subjects; nonetheless, it has shown to be effective in teaching scientific concepts and contributing to the success of students in the sciences (Congos \& Mack, 2005; Gaddis, 1994; Gattis, 2002; Lundeberg, 1990; Lundeberg \& Moch, 1995; Parkinson, 2009).

\section{Methodology and Research Design}

The quantitative approach of this study was selected due to the experimental nature of the research which determines if an intervention influences a certain outcome (Creswell, 2009). More specifically, the study assessed how the SI program impacted Hispanic students who participated as determined through final grades or course completion rates and if there was a difference between attendance and gender (Creswell, 2009). The statistical procedures that were used were the One-Way and Two-way Analysis of Variance (ANOVA). Students in the courses selected were not randomly assigned by the researcher defining this as a non-experimental study, but most importantly it infers a correlation relationship (Crowl, 1986). This study analyzed: 1) three groups of SI attendance, 2) final course grade, 3) course taken, and 4) gender.

The department of education awarded this particular HSI a cooperative grant award of $\$ 1.2$ million per year for up to two years (HACU, 2010). One of the intents of the federal grant was to increase the number of Hispanic and low income students attaining degrees in the fields of science, technology, engineering, and mathematics. Through this grant, the SI program was fully funded in support of science, mathematics, and engineering gateway courses for two academic years. SI sessions were held three times a week for an hour throughout the semester for each identified course and were facilitated by a trained SI leader. The SI sessions were designed to get students working together to help develop strategies to master course content, review class material and prepare for exams. Study strategies were used to teach note taking, organization, questioning techniques, vocabulary, and test preparation as students reviewed the course material with their classmates. Attendance at SI sessions is voluntary and recorded by student identification number on sign-in sheets that were provided by the SI leaders.

Supplemental Instruction targets courses that have been designated to be barrier courses and have a $30 \%$ or higher D or F grades or withdrawal rates among students (Blanc, Debuhr \& Martin, 1983). At this particular HSI, University Physics and Inorganic Chemistry were courses that fell into the $30 \%$ criteria. The Physics course analyzed was Physics 2325: University Physics I. The Chemistry course analyzed was Chemistry 1311: General Inorganic Chemistry I. These courses were identified as at-risk courses and were supported by the SI program. The population of the study consisted of a total of 601 undergraduate students enrolled in Inorganic Chemistry I and University Physics I courses during the 2009-2010 year. There were a total of 415 students in Chemistry and 186 students in Physics.

The sample for the study was a total of 357 Hispanic students, with 261 enrolled in Inorganic Chemistry I and 96 enrolled in University Physics I. The sample identified SI participants and non-SI participants within the courses selected. In Chemistry there were 161 (61\%) SI participants and $100(38 \%)$ non-SI participants. In Physics, there were $62(65 \%)$ SI participants and $34(35 \%)$ non-SI participants. Attendance records, level of SI attendance, and final grades were requested and provided by the Supplemental Instruction office at the Title V Grant office. Gender and ethnicity information were requested and provided by the Office of Institutional Research at the institution.

Supplemental Instruction sessions were offered to all students enrolled in the designated sections of Inorganic Chemistry I and University Physics I courses and was a free academic support service to all students. Therefore, there were no incentives given to students in order to attend SI sessions. There were 42 possible SI sessions per semester for students to attend or approximately 84 sessions for the academic year. The selection process in this study was based on students that were enrolled in the course and were identified with the institution as Hispanic 
students. The participants were not randomly assigned, but instead they were self-selected based on enrollment in the course and level of SI attendance.

\section{Results}

\subsection{SI Effect on Final Grades}

In order to investigate whether SI attendance had an impact on final course grades and course completion rates of Hispanic students at a HSI, a One-way ANOVA and a Two-way ANOVA procedure were used to analyze the data. The variables that were analyzed in this study include: 1) three groups of SI attendance, 2) final course grade, 3) course taken, and 4) gender. The independent variables were the number of SI sessions attended, which were divided into three groups. The non-SI group $=0$, the low group $=1-10$ SI sessions attended, and the high group $=11$ or more SI sessions attended in one semester. The final grade was defined as: $\mathrm{A}=5, \mathrm{~B}=4, \mathrm{C}=3, \mathrm{D}=2, \mathrm{~F}=1, \mathrm{Q}=0$. In addition, gender (male or female) was an independent variable. The dependent variables were the following: course completion rates and final course grades for this study.

The One-way ANOVA statistical test was used in order to answer research question one: Does the number of SI session level have an effect on the final course grade in physics and chemistry for Hispanic students? A One-way ANOVA was conducted to assess whether final grade means, the dependent variable, were significantly different among the SI attendance levels (non-SI, low-SI, and high-SI), or groups. The SI attendance level variable was solely based on total number of SI sessions attended with the mean score for the classes in chemistry or physics. The means and standard deviations for final grades based on SI attendance levels for Inorganic Chemistry I and University Physics I are noted in Table 1.

Table 1: Means and Standard Deviations for Final Grades

\begin{tabular}{lllll}
\hline \multirow{2}{*}{ Course Number } & Session & Attendance & & SD \\
\hline CHEM 1311 & Level & Mean & 1.569 & 100 \\
& Non-SI & 1.73 & 1.532 & 120 \\
\multirow{2}{*}{ PHYS 2325 } & Low & 2.85 & 1.243 & 41 \\
& High & 3.61 & 1.351 & 34 \\
& Non-SI & 1.59 & 1.348 & 49 \\
& Low & 2.12 & 1.261 & 13 \\
\hline
\end{tabular}

The means for course final grades showed an increase between non-SI to low and low to high for both courses. As SI attendance increased so did the final grades among Hispanic students.

In Inorganic Chemistry I (CHEM 1311), the mean for final grades increased from the non-SI group $(M=1.73, S D=$ $1.57)$, to the low SI level $(M=2.85, S D=1.53)$, to the high SI level $(M=3.61, S D=1.24)$. The descriptive data allowed us to assume there was one letter grade higher between the non-SI to low SI and two letter grades higher between the non-SI to high SI levels for chemistry.

In University Physics I (PHYS 2325) courses, the mean of the final grades increased from the non-SI level $(M=1.59$, $S D=1.35)$, to the low SI level $(M=2.12, S D=1.35)$, to the high SI level $(M=3.62, S D=1.26)$. The descriptive data revealed a final grade increase between the non-SI to low SI attendance level and the non-SI group to high SI attendance levels for physics. Again, the increase was approximately one letter grade improvement between the non-SI group to the low attendance level and two letter grades more between the non-SI group and the high attendance levels in physics.

\subsection{SI Effect on Chemistry Final Grades}

A One-way ANOVA was conducted to evaluate the effects the SI session attendance level had on final grades in Inorganic Chemistry I. The One-way ANOVA indicated there was significance $F(2,258)=27.37, p<.00$, partial $\eta^{2}$ $=.175$. Since the data confirmed there was a significant difference among the SI session level means on final grades and the overall $\mathrm{F}$ test was significant, follow-up tests were conducted. The post hoc tests were conducted to analyze 
the effect of SI session attendance levels by examining if a certain SI level (non-SI, low, or high) was more effective in increasing final grades among Hispanic students.

The results of this analysis indicated that there was a significant difference in final grade means between the non-SI level $(M=1.73, S D=1.57)$ and the low SI level $(M=2.85, S D=1.53), p<.05$. There was also a significant difference in final grade means between non-SI $(M=1.73, S D=1.57)$ and high $\mathrm{SI}$ attendance levels $(M=3.61, S D=$ $1.24), p<.05$. Likewise, there was a significant difference in final grades between low SI level $(M=2.85, S D=1.53)$ and high SI level $(M=3.61, S D=1.24), p<.05$. SI participation did make a difference in chemistry final grades for Hispanic students. The results of this comparison supported the research hypothesis. There were significant differences among non-SI, low, and high attendance at SI sessions on Chemistry final course grade for Hispanic students (non-SI attendance $<$ low attendance $<$ high attendance).

\subsection{SI Effect on Physics Final Grades}

A One-way ANOVA was conducted to evaluate the effect the SI session attendance level had on final grades in University Physics I. The One-way ANOVA indicated there was significance $F(2,93)=10.79, p<.00$, partial $\eta^{2}$ $=.188$. Since the data confirmed there was a significant difference among the SI session level means on final grades and the overall $\mathrm{F}$ test was significant, follow-up tests were conducted. The post hoc tests were conducted to analyze the effect of SI session attendance levels by examining if a certain SI level (non-SI, low, or high) was more effective in increasing final grades in Physics among Hispanic students. The results are found in Table 2.

Table 2: Multiple Comparisons for SI Session Levels Effect on Physics Final Grades

\begin{tabular}{lllll}
\hline & Session & Session & & \\
& Attendance & Attendance & Mean & \\
& Level & Level & Difference & Sig. \\
\hline Tukey HSD & \multirow{2}{*}{ Non-SI } & Low & -.53 & .179 \\
& Low & High & $-2.03^{*}$ & .000 \\
& High & $-.1 .49^{*}$ & .002 \\
\hline
\end{tabular}

*The mean difference is significant at the .05 level.

Surprisingly, the results of this analysis indicated that there was no significant difference in final grades between the non-SI level $(M=1.59, S D=1.35)$ and the low SI level $(M=2.12, S D=1.35), p=.18$. Alternatively, there was a significant difference in final grade means between non-SI $(M=1.59, S D=1.35)$ and high SI attendance levels $(M=$ 3.62, $S D=1.26), p<.05$. Similarly, there was a significant difference in final grades between low SI level $(M=1.59$, $S D=1.35)$ and high SI level $(M=3.62, S D=1.26), p<.05$. SI participation made a difference in physics final grades for Hispanic students between those who did not attend SI sessions and those who attended 11 or more SI sessions. Additionally, there was a significant difference in mean final grades between those students who attended 1-10 sessions and those attending 11 or more sessions (non-SI attendance $<$ high attendance; low attendance $<$ high attendance)).

\subsection{SI Effect in Physics Course Completion}

A Two-way ANOVA statistical test was conducted to answer research question two: What are the main effects of supplemental instruction and gender on physics course completion and is there any interaction between instruction and gender? The means and standard deviations for course completion in Physics as a function of the two factors, SI attendance and gender, are presented in Table 3.

Table 3: Means and Standard Deviations for Physics Course Completion

\begin{tabular}{lllll}
\hline & Session & & & \\
Gender & Attendance Level & Mean & SD & $\mathrm{N}$ \\
\hline Male & Non-SI & .39 & .50 & 28 \\
& Low & .65 & .49 & 34 \\
Female & High & .91 & .30 & 11 \\
& Non-SI & .33 & .52 & 6 \\
& Low & .67 & .49 & 15 \\
\hline
\end{tabular}

The descriptive data indicated a steady increase of physics course completion means from the non-SI group to low SI level and low SI level to high SI attendance level with both males and females. The means for male course completion increased from the non-SI level $(M=.39, S D=.50)$, to the low SI level $(M=.65, S D=.49)$, to the high 
SI level $(M=.91, S D=.30)$. Similarly, there was an increase in course completion means among female students from the non-SI level $(M=.33, S D=.52)$, to the low SI level $(M=.67, S D=.49)$, to the high SI level $(M=1.00, S D$ $=.00)$.

A Two-way ANOVA was conducted to evaluate SI attendance levels and gender main effects on physics course completion. Physics course completion was chosen as the dependent variable and gender and SI session levels were chosen as factors. The Two-way ANOVA indicated no significant interaction between SI attendance levels and gender, $F(2,90)=.079, p=.924$, partial $\eta^{2}=.002$ and no significant main effect for gender, $F(1,90)=.013, p=.909$, partial $\eta^{2}=.000$. There was a significant main effect for SI session level, $F(2,90)=4.71, p<.05$, partial $\eta^{2}=.095$. The effect size for the SI session level analysis was medium to large $\eta^{2}=.095$, meaning that $10 \%$ of the variance in course completion was due to supplemental instruction. It was determined that there was no difference in course completion means between Hispanic males and females. However, the results indicated there was a significant difference in means of course completion between the SI attendance levels.

Post hoc tests were conducted on the significant main effect of SI session levels to examine if a certain SI level (non-SI, low, or high) was more effective for course completion in physics. The results of the pairwise comparison indicated that there were significant differences in physics course completion means between the non-SI $(M=.38$, $S D=.49)$ and the low SI levels $(M=.65, S D=.48), p<.05$, and between the non-SI $(M=.38, S D=.49)$ and high SI level $(M=.92, S D=.28), p<.05$. There was no significant difference in physics completion between the low SI $(M$ $=.65, S D=.48)$ and high SI level $(M=.92, S D=.28), p=.164$. It was determined that there were significant differences in physics course completion between Hispanic students who did not participate and those who participated in SI sessions (non-SI attendance < low attendance; non-SI attendance $<$ high attendance). Hispanic students who participated in SI had higher course completion means in physics than those who did not participate in SI. It appeared that the number of sessions did not make a difference in physics course completion.

\subsection{SI Effect in Chemistry Course Completion}

A Two-way ANOVA statistical test was conducted to answer research question three: What are the main effects of supplemental instruction and gender on chemistry course completion and is there any interaction between instruction and gender? In Table 4, the means and standard deviations for course completion in chemistry as a function of the two factors, SI attendance and gender, are presented.

Table 4: Means and Standard Deviations for Chemistry Course Completion

\begin{tabular}{lllll}
\hline Gender & Session Attendance Level & Mean & SD & N \\
\hline \multirow{3}{*}{ Male } & Non-SI & .46 & .50 & 63 \\
& Low & .79 & .41 & 68 \\
& High & .93 & .26 & 28 \\
Female & Non-SI & .27 & .45 & 37 \\
& Low & .81 & .40 & 52 \\
& High & 1.00 & .00 & 13 \\
\hline
\end{tabular}

The descriptive data indicated a steady increase of course completion means between the non-SI group to low SI attendance levels and low to high SI attendance levels with both males and females. Male student course completion mean increased from the non-SI group $(M=.46, S D=.50)$, to the low SI level $(M=.79, S D=.41)$, to the high SI level $(M=.93, S D=.26)$ and increased for female students from the non-SI group $(M=.27, S D=.45)$, to the low SI level $(M=.81, S D=.40)$, to the high SI level $(M=1.00, S D=.00)$.

A Two-way ANOVA was conducted to evaluate SI session attendance levels and gender main effects and the interaction between SI level and gender on chemistry course completion. Chemistry course completion was chosen as the dependent variable and gender and SI session levels were chosen as factors. The Two-way ANOVA indicated no significant interaction between SI attendance levels and gender, $F(2,255)=2.05, p=.132$, partial $\eta^{2}=.016$ and no significant main effect for gender, $F(1,255)=.338, p=.562$, partial $\eta^{2}=.001$. There was a significant main effect for SI session level, $F(2,255)=39.78, p<.05$, partial $\eta^{2}=.238$. It was determined that there was no difference in chemistry course completion means between Hispanic males and females. Conversely, there was a significant difference in means of chemistry course completion between SI attendance levels.

Post hoc tests were conducted on the significant main effect of SI session levels to examine if a certain SI level (non-SI, low, or high) was more effective for course completion in chemistry. The results are shown in Table 5. 
Table 5: Multiple Comparisons for SI Session Levels in Chemistry Course Completion

\begin{tabular}{lllll}
\hline & Session & Session & \multirow{2}{*}{ Mean Difference } & Sig. \\
\hline Attendance Level & Attendance Level & $.41^{*}$ & .000 \\
Tukey HSD & \multirow{2}{*}{ Non-SI } & Low & $.56^{*}$ & .000 \\
& Low & High & .15 & .111 \\
\hline
\end{tabular}

*The mean difference is significant at the .05 level.

The results of the pairwise comparison indicated that there was a significant difference in chemistry course completion means between the non-SI $(M=.39, S D=.49)$ and the low SI level $(M=.80, S D=.40), p<.05$ and between non-SI $(M=.39, S D=.49)$ and high SI level $(M=.95, S D=.22), p<.05$. There was no significant difference in chemistry course completion means between the low SI level $(M=.80, S D=.40)$ and high SI level $(M$ $=.95, S D=.22), p=.111$. The results indicated there were significant differences in chemistry course completion means between Hispanic students who did not participate and those who participated in SI sessions (non-SI attendance $<$ low attendance; non-SI attendance $<$ high attendance). The Hispanic students who participated in SI have higher course completion means in chemistry. The number of sessions did not make a significant difference in chemistry course completion.

\section{Discussion}

With current college graduation initiatives, HSIs are in a critical position to promote post-secondary opportunity and create an economic recovery among Hispanics. Gastic and Nieto (2010) maintain that successful HSIs incorporate academic support services to build effective support environments around their students. Research has pointed to the effectiveness of the academic support program, Supplemental Instruction, whether it be by assessing variables such as academic preparedness, student motivation, (McCarthy A., \& Smuts B, 1997) student disciplines, mandatory or voluntary SI sessions, by differing ethnic groups, or disadvantaged or high-achieving groups; SI participants clearly outperform their peers (Blanc, Debuhr \& Martin, 1983; Congos \& Schoeps, 1993; Hodges \& White, 2001; McCarthy \& Smuts, 1997; Ogden, Thompson, Russell \& Simons, 2003; Ramirez, 1997). However, there is little SI research on its effectiveness with Hispanic student success. The results to this study not only supported the existing research on SI's effectiveness in increasing academic success, but most importantly it contributed to SI's effectiveness among Hispanic populations. This is an essential addition to the SI research as institutions of higher education seek to implement innovative practices that increase student learning, academic success, persistence, and degree attainment among Hispanic students.

The first section of the study evaluated SI's impact on final grades in Inorganic Chemistry I and University Physics I among Hispanic students. A One-Way ANOVA was conducted to assess whether final grades were significantly different among SI attendance levels. The results showed a significant effect between SI levels and final grades in both chemistry and physics. However, when follow-up tests were conducted to evaluate pairwise differences among the SI attendance level means there were significant differences among non-SI, low, and high attendance at SI sessions in Chemistry, but surprisingly there was no significant difference in Physics final grades between the non-SI level and the low SI level. There was a significant difference in Physics final grade means between non-SI and high SI attendance levels and between low SI level and high SI level.

Student success in college physics has been a topic of concern for physics educators for decades. Research has found a relationship between high school physics courses and college physics grades (Sadler \& Tai, 2001). While Sadler and Tai found that students appear to do better in college physics if they have taken rigorous high school physics courses, many high school students are not taking even a full year of physics in high school (College freshman, 2009). Further, many students' personal conceptual models of physics contain many misconceptions and misunderstandings based on their observations of the natural world (Halloun \& Hestenes, 1985). These misconceptions can be highly resistant to change and can impact college performance without intervention from SI programs. Finally, while no data was kept on when students accessed SI in this study, accessing SI early in the course may be of greater benefit than later in the course. As with many sciences, knowledge in physics is cumulative and additive (Courtney, Althausen, \& Courtney, 2007); if students in the 1-10 level of SI accessed the SI later in the course, it may have been too little, too late.

Additionally, the study evaluated SI's impact on course completion in Inorganic Chemistry I and University Physics I among Hispanic students. A Two-way ANOVA was run to determine course completion in both courses based on 
SI attendance levels and gender. The results indicated no significant main effect for gender and no significant interaction effect between SI attendance levels and gender. There was a significant main effect for SI attendance level in chemistry and physics course completion. After conducting follow-up tests, the results showed a significant difference in course completion between Hispanic students who attended SI sessions and those Hispanic students who did not attend SI sessions. As long as Hispanic students participated in SI, regardless of the number of times they attended, their course completion rate increased. The results support when Hispanic students participate in SI sessions they are more likely to complete Inorganic Chemistry and University Physics I. However, in the area of completion, the results may also suggest that students who attend no sessions of SI may have a lack of prior knowledge in these areas and/or a lack of motivation. This would lead to completing future research controlling for prior knowledge in the areas of chemistry and physics and in student motivation.

\section{Conclusions}

With national attention on retention and graduation rates and federal-state initiatives being placed on the science, technology, engineering, and math (STEM) pipeline, there is a great need for academic support programs that are not only cost-effective but increase student success and persistence in the sciences at Hispanic-serving institutions (HSIs). It is imperative that HSIs, having a high percentage of Hispanic populations, find ways where they will support and retain this growing number of degree-seeking students. It is essential that academic support programs such as Supplemental Instruction are available to help such students succeed academically.

\section{References}

American College Test (ACT). (2010). What works in student retention? Fourth national survey: Report for all colleges and universities (Research Report). Iowa City, IA.

Anderson, E., \& Kim, D. (2006). Increasing the success of minority students in science and technology. Washington, DC: American Council on Education.

Bell, T., Urhahne, D., Schanze, S., \& Ploetzner, R. (2010). Collaborative inquiry learning: Models, tools, and

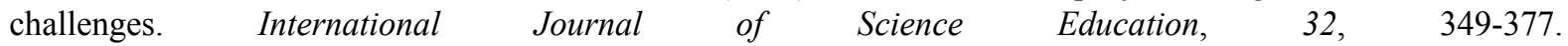
http://dx/doi.org/10.1080/09500690802582241

Benitez, M., \& DeAro, J. (2004). Realizing student success at Hispanic-serving institutions. New Directions for Community Colleges, 127, 35-48. http://dx.doi.org/10.1002/cc.162

Blanc, R. A., \& Martin, D. C. (1994). Supplemental Instruction: Increasing student performance and persistence in difficult academic courses. Journal of the Association of American Medical Colleges, 69, 452-454. http://dx.doi.org/10.1097/00001888-199406000-00004

Blanc, R. A., Debuhr, L. E., \& Martin, D. C. (1983). Breaking the attrition cycle: The effects of supplemental instruction on undergraduate performance and attrition. Journal of Higher Education, 54(1), 80-90. http://dx.doi.org/10.2307/1981646

Boud, D., Cohen, R., \& Sampson, J. (1999). Peer Learning and Assessment. Assessment \& Evaluation in Higher Education, 24(4), 413-426.

Cerna, O. S., Perez, P. A., \& Saenz, V. (2009). Examining the precollege attributes and values of Latina/o bachelors degree attainers. Journal of Hispanic Higher Education, 8, 130-157. http://dx.doi.org/10.1177/1538192708330239

College Freshmen In US And China: Chinese Students Know More Science Facts But Neither Group Especially Skilled In Reasoning. (2009, October 29). Science Daily: News \& Articles in Science, Health, Environment \& Technology. Retrieved July 1, 2012, from http://www.sciencedaily.com/releases/2009/01/090129140840.htm

Collins, W. (1982). Some correlates of achievement among students in a supplemental instruction program. Journal of Learning Skills, 2(1), 19-28.

Congos, D. H. (2002). How supplemental instruction stacks up against Chickering's 7 principles for good practice in undergraduate education. Research and Teaching in Developmental Education, 19(1), 75-83.

Congos, D. H., \& Mack, A. (2005). Supplemental Instruction's impact on students in two freshmen chemistry classes. Research and Teaching in Developmental Education, 21(2), 43-64. 
Congos, D. H., \& Schoeps, N. (1993). Does supplemental instruction really work and what is it anyway? Studies in Higher Education, 18(2), 165-176.

Congos, D. H., \& Schoeps, N. (1999). Methods to determine the impact of si programs on colleges and universities. The Journal of College Student Retention: Research, Theory and Practice, 1(1), 59-82. http://dx.doi.org/10.2190/4R98-H5KD-8HXK-J4WF

Courtney, M., Althausen, N., \& Courtney A. (2007). Five Frequently Fatal Freshman Physics Fantasies. Physics Education, 42(1), 116.

Creswell, J.W. (2009). Research design: Qualitative, quantitative, and mixed methods approaches (3 ${ }^{\text {rd }}$ ed.). Thousand Oaks, CA: Sage Publications, Inc.

Crisp, G., Nora, A., \& Taggart, A. (2009). Student characteristics, pre-college, college, and environmental factors as predictors of majoring in and earning a STEM degree: An analysis of students attending a Hispanic-serving institution. American Educational Research Journal, 46, 924-942. http://dx.doi.org/10.3102/0002831209349460

Crowl, T. K. (1986). Fundamentals of research: A practical guide for educators and special educators. Columbus, OH: Publishing Horizons, Inc.

Fischer, M. J. (2007). Settling into campus life: Differences by race/ethnicity in college involvement and outcomes. The Journal of Higher Education, 78, 125-161. http://dx.doi.org/10.1353/jhe.2007.0009

Fuertes, J. N., \& Sedlacek, W. E. (1995). Using noncognitive variables to predict the grades and retention of Hispanic students. College Student Affairs Journal, 14(2), 30-36.

Gaddis, B. A. (1994). The science learning center. Education, 115, 195-201.

Gastic, B., \& Nieto, D. G. (2010). Latinos' economic recovery: Postsecondary participation and Hispanic-serving institutions. Community College Journal of Research and Practice, 34, 833-838. http://dx.doi.org/10.1080/10668921003781043

Gates, A. Q. (2010). Broadening participation: The role of Hispanic-serving institutions in contributing to an educated work force. Communications of the Association for Computing Machinery (ACM), 53(12), 31-33. http://dx.doi.org/10.1145/1859204.1859217

Gattis, Kenneth W. (2002). Responding to Self-Selection Bias in Assessments of Academic Support Programs: A Motivational Control Study of Supplemental Instruction. Learning Assistance Review, 7(2), 26-36.

Green, D. (2006). Historically underserved students: What we know, what we still need to know. New Directions for Community Colleges, 135, 21-28. http://dx.doi.org/10.1002/cc.244

Haegedorn, L. S., Chi, W., Cepeda, R. M., \& McLain, M. (2007). An investigation of critical mass: The role of Latino representation in the success of urban community college students. Research in Higher Education, 48(1), 73-92. http://dx.doi.org/10.1007/s11162-006-9024-5

Halloun, I., \& Hestenes, D. (1985). The Initial Knowledge State of College Physics Students. American Journal of Physics, 53, 1043-1055 http://dx.doi.org/10.1119/1.14030

Hispanic Association of Colleges \& Universities (HACU). (2010). College cost reduction access act grant application. Retrieved from http://www.hacu.net/hacu/CCRAAHSI

Hodges, R., \& White, W. (2001). Encouraging high-risk student participation in tutoring and supplemental instruction. Journal of Developmental Education, 24(3), 2-10.

Hurley, M., Jacobs, G., \& Gilbert, M. (2006). The basic SI model. New Directions for Teaching and Learning, 106, 11-22. http://dx.doi.org/10.1002/t1.229

Hurtado, S., \& Ponjuan, L. (2005). Latino educational outcomes and the campus climate. Journal of Hispanic Higher Education, 4, 235-251. http://dx.doi.org/10.1177/1538192705276548

Kenney, P. A., \& Kallison Jr., J. M. (1994). Research studies on effectiveness of supplemental instruction in mathematics. New Directions for Teaching and Learning, 60, 75-81. http://dx.doi.org/10.1002/tt.37219946010

Kuh, G. D., Cruce, T. M., Shoup, R., Kinzie, J., \& Gonyea, R. M. (2008). Unmasking the effects of student engagement on first-year college grades and persistence. Journal of Higher Education, 79(5), 540-560.

Laden, B. V. (2004). Hispanic-serving institutions: What are they? Where are they? Community College Journal of 
Research and Practice, 28, 181-198. http://dx.doi.org/10.1080/10668920490256381

Longerbeam, S. D., Sedlacek, W. E., \& Alatorre, H. M. (2004). In their own voices: Latino student retention. NASPA Journal, 41, 538-550.

Lundeberg, M. A. (1990). Supplemental Instruction in chemistry. Journal of Research in Science Teaching, 27, 145-155. http://dx.doi.org/10.1002/tea.3660270206

Lundeberg, M. A., \& Moch, S. D. (1995). Influence of social interaction on cognition: Connected learning in science. Journal of Higher Education, 66, 312-335. http://dx.doi.org/10.2307/2943894

Maestas, R., Vaquera, G. S., \& Zehr, L. M. (2007). Factors impacting sense of belonging at a Hispanic-serving institution. Journal of Hispanic Higher Education, 6, 237-256. http://dx.doi.org/10.1177/1538192707302801

McCarthy, A., \& Smuts, B. (1997). Assessing the effectiveness of supplemental instruction: A critique and a case study. Studies in Higher Education, 22, 221-231. http://dx.doi.org/10.1080/03075079712331381054

McGee, J. V. (2005). Cognitive, demographic, and motivational factors as indicators of help-seeking in supplemental instruction (Doctoral dissertation 3172055).

McGlynn, A. P. (2009). Proven pathways to success for minority students. Education Digest: Essential Readings Condensed for Quick Review, 74(9), 42-45.

Morgan, B. M. (2004). Cooperative learning in higher education: Hispanic and non-Hispanic undergraduates' reflections on group grades. Journal of Latinos and Education, 3(1), 39-52. http://dx.doi.org/10.1207/s1532771xjle0301_4

National Science Foundation, Division of Sciences Resource Statistics, Women, minorities, and persons with disabilities in science and engineering: 2009, NSF 09-305, (Arlington, VA; January 2009). Retrieved from http://www.nsf.gov/statistics/wmpd/

O'Connor, N. (2009). Hispanic origin, socio-economic status, and community college enrollment. The Journal of Higher Education, 80, 121-144. http://dx.doi.org/10.1353/jhe.0.0038

Ogden, P., Thompson, D., Russell, A., \& Simons, C. (2003). Supplemental instruction: Short- and long-term impact. Journal of Developmental Education, 26(3), 2-6.

Oseguera, L., Locks, A. M., \& Vega, I. I. (2009). Increasing Latina/o students' baccalaureate attainment: A focus on retention. Journal of Hispanic Higher Education, 8(23), 23-48. http://dx.doi.org/10.1177/1538192708326997

Parkinson, M. (2009). The effect of peer assisted learning support (pals) on performance in mathematics and chemistry. Innovations in Education and Teaching International, 46, 381-392. http://dx.doi.org/10.1080/14703290903301784

Pascarella, E. T., Pierson, C. T., Wolniak, G. C., \& Terenzini, P. T. (2004). First-generation students: Additional evidence on college experiences and outcomes. The Journal of Higher Education, 75, 249-284. http://dx.doi.org/10.1353/jhe.2004.0016

Perrakis, A., \& Hagedorn, L. S. (2010). Latino/a student success in community colleges and Hispanic-serving institution status. Community College Journal of Research and Practice, 34, 797-813. http://dx.doi.org/10.1080/10668921003723110

Ramirez, G. M. (1997). Supplemental instruction: The long-term impact. Journal of Developmental Education, 21(1), $2-10$.

Rath, K.A., Peterfreund, A.R., Xenos, S.P., Bayliss, F., \& Carnal, N. (2007). Supplemental instruction in introductory biology I: Enhancing the performance and retention of underrepresented minority students. $C B E$ Life Sciences Education, 6, 203-216.

Sadler, Philip M., \& Robert H. Tai. (2001). Success in Introductory College Physics: The Role of High School Preparation. Science Education, 111-136. http://dx.doi.org/10.1002/1098-237X(200103)85:2<111::AID-SCE20>3.3.CO;2-F

Santiago, D. A (2008). The condition of Latinos in education: 2008 fact book. Washington, DC: Excelencia in Education.

Seymour, E. (2002). Tracking the processes of change in US undergraduate education in science, mathematics, engineering, and technology. Science Education, 85, 79-105. http://dx.doi.org/10.1002/sce.1044 
Seymour, E., \& Hewitt, N. (1997). Talking about leaving: Why undergraduates leave the sciences. Boulder, CO: Westview Press.

Shaya, S. B., Petty, H. R., \& Petty, L. I. (1993). A case study of supplemental instruction in biology focused on at-risk students. BioScience, 43, 709-711. http://dx.doi.org/10.2307/1312343

Sweeney, A., Weaven, S., \& Herington, C. (2008). Multicultural influences on group learning: A qualitative higher education study. Assessment \& Evaluation in Higher Education, 33, 119-132. http://dx.doi.org/10.1080/02602930601125665

Terenzini, P. T. (1994). Educating for citizenship: Freeing the mind and elevating the spirit. Innovative Higher Education, 19, 7-21. http://dx.doi.org/10.1007/BF01191154

Tinto, V. (1986). Theories of student departure revisited. In J. Smart (Ed.), Higher Education: Handbook of theory and research, (359-384). New York, NY: Agathon Press.

Tinto, V. (1994). Leaving college: Rethinking the causes and cures of student attrition (2 ${ }^{\text {nd }}$ ed.). Chicago: The University of Chicago Press.

Torres, V. (2006). Bridging two worlds: Academia and Latina/o identity. In J. Castellanos, A. Gloria, \& M. Kamimura (Eds.), The Latina/o pathway to the Ph.D: Abriendo caminos (pp.135-147). Sterling, VA: Stylus.

U.S. Bureau of the Census. (2010a). College enrollment by sex, age, race, and Hispanic origin: 1980 to 2007. Retrieved from http://www.census.gov/compendia/statab/2010/tables/10s0272.pdf

U.S. Bureau of the Census. (2010b). 2008 national population projections. Retrieved from http://www.census.gov/compendia/statab/2010/tables/10s0011.pdf

U.S. Department of Education. (2010). Developing Hispanic-serving institutions Program - Title V: Definition of Hispanic-serving institutions. Retrieved from http://www2.ed.gov/programs/idueshsi/definition.html

U.S. Department of Education, National Center for Education Statistics, Integrated Postsecondary Education Data System (IPEDS), Spring 2003 and Spring 2009, Graduation Rates component. (NCES 2011), Indicator 23-2011.

Violino, B. (2011). Hispanics and stem. Communications of the Association Computing Machinery (ACM), 54(1), 19.

Widmar, G. E. (1994). Supplemental instruction: From small beginnings to a national program. New Directions for Teaching and Learning, 60, 3-10. http://dx.doi.org/10.1002/t1.37219946003

Wilcox, K. F., \& Koehler, C. (1996). Supplemental Instruction: Critical thinking and academic assistance. Metropolitan Universities: An International Forum, 6(4), 87-99.

Wolfe, R. F. (1987). The supplemental instruction program: Developing learning and thinking skills. Journal of Reading, 31, 228-232. 